\title{
The Odessa Sky Patrol Plate Collection
}

V.G. Karetnikov, A.K. Markina, V.P. Sotnikov

Astronomical Observatory of Odessa State University

The Odessa Astronomical Observatory has three collections of Sky Patrol negatives, which have been exposed since the beginning of the 20th century. Altogether, there are about 100,000 negatives of the stellar sky, covering a declination range from -15 to $+90^{\circ}$. The limiting stellar magnitudes are 15 (photographic $-\mathrm{pg}$ ) and 12 (photovisual - pv), respectively.

Table 1. Characteristics of the Simeiz 2-camera astrograph: Date of observations is from JD 2418405 to 2434725 (1909-1953)

\begin{tabular}{cccccccr}
\hline $\begin{array}{c}\text { Type of } \\
\text { objective cameras }\end{array}$ & $\begin{array}{c}\text { No. of } \\
\text { in }\end{array}$ mm & $\begin{array}{c}\text { Plate } \\
\text { in cm }\end{array}$ & $\begin{array}{c}\text { Field } \\
\text { in }\end{array}$ & $\begin{array}{c}\text { Limit magn. } \\
\text { Photom. syst. }\end{array}$ & $\begin{array}{r}\text { Centre } \\
\text { in }\end{array}$ \\
\hline UNAR & $1 \& 2$ & 120 & 600 & $13 \times 18$ & $12 \times 17$ & $<9.2 \mathrm{pg}$ & 0 \\
\hline
\end{tabular}

Table 2. Characteristics of old astrographs of Odessa Observatory: Date of observations is from JD 2433812 to 2435776 (1951-1956)

\begin{tabular}{|c|c|c|c|c|c|c|c|}
\hline $\begin{array}{c}\text { Name of } \\
\text { instrument }\end{array}$ & $\begin{array}{l}\text { No. of } \\
\text { cameras }\end{array}$ & $\begin{array}{c}\text { Type of } \\
\text { objective }\end{array}$ & $\begin{array}{l}\mathrm{D} \\
\text { in }\end{array}$ & $\begin{array}{l}\& \mathrm{~F} \\
\mathrm{~mm}\end{array}$ & $\begin{array}{l}\text { Field } \\
\text { in }^{\circ}\end{array}$ & $\begin{array}{l}\text { Photom. } \\
\text { system }\end{array}$ & $\begin{array}{c}\text { Center } \\
\text { in }\end{array}$ \\
\hline $\begin{array}{c}\text { "Large" } \\
\text { astrograph }\end{array}$ & 1 & Tessar SOI & 148 & 1000 & $9 \times 12$ & $\mathrm{pg}$ & 0 \\
\hline "Small" & 1 & Indu & 100 & 500 & $22 \times 15$ & $\mathrm{pg}$ & 0 \\
\hline astrograpl & 2 & Triplet Zeiss & 100 & 500 & $22 \times 15$ & $\mathrm{pg}, \mathrm{pv}$ & 0 \\
\hline Astrograp & 1 & Industar-163 & 67 & 300 & $20 \times 30$ & pv & 0 \\
\hline \multirow{2}{*}{ "Hedgehog" } & 2 & Xenon & 60 & 120 & $20 \times 30$ & pv & -25 \\
\hline & 3 & Epostar & 60 & 120 & $20 \times 30$ & pv & +25 \\
\hline
\end{tabular}


1. The first of the three collections is the "Simeiz" collection obtained at the 2-camera astrograph in Crimea at the beginning of the century (about 10000 plates) to discover and study small planets and comets. The field centers are determined by the position of small planets and comets and by their expected region of presence. Coordinates are indicated on the plate envelopes.

2. The second archive of similar size consists of negatives obtained at the "old" astrographs of the Odessa Observatory. There is a small number of plates exposed in photored light (pr). For these plates we have different guide stars. These stars are indicated on the plate envelopes. The plate centers listed in Table 2 are given as offset relative to the corresponding guide star (in degrees of declination).

3. The third archive is obtained from observations of the "7-camera" astrograph in Odessa which have started in 1957 and are continued until now. It contains about 80000 negatives. For this archive, there is an electronic version of the catalogue which contains the numbers of the negatives and exposure times. The plates were separated into three series: Old, New, III series (see Tables $3,4)$. In the Old series the following 25 guide stars were used:

Table 3. Characteristics of the 7-camera astrograph: Dates of observations is from JD 2436039 (1957) until now

\begin{tabular}{|c|c|c|c|c|c|c|c|}
\hline $\begin{array}{c}\text { Name \& } \\
\text { Data }\end{array}$ & $\begin{array}{c}\text { No. of } \\
\text { cameras }\end{array}$ & $\begin{array}{l}\text { Type of } \\
\text { objective }\end{array}$ & $\begin{array}{l}\mathrm{D} \\
\text { in }\end{array}$ & $\underset{\mathrm{mm}}{\&} \mathrm{~F}$ & $\begin{array}{l}\text { Field } \\
\text { in }^{\circ}\end{array}$ & $\begin{array}{c}\text { Photom. } \\
\text { system }\end{array}$ & $\begin{array}{r}\text { Center } \\
\text { in }\end{array}$ \\
\hline The Old & 1 & Uran-9 & 100 & 250 & $30 \times 40$ & $\mathrm{pg}, \mathrm{pv}$ & +13 \\
\hline series. & 2 & Uran-9 & 100 & 250 & $30 \times 40$ & pg,pv & -13 \\
\hline From & 3 & Uran-9 & 100 & 250 & $35 \times 25$ & $\mathrm{pg}$ & +25 \\
\hline 19.07 .1957 & 4 & Vierlinser & 160 & 720 & $13 \times 18$ & pg & +08 \\
\hline to & 5 & Vierlinser & 160 & 720 & $13 \times 18$ & pg & -08 \\
\hline \multirow[t]{2}{*}{08.04 .1959} & 6 & Uran-9 & 100 & 250 & $30 \times 40$ & pg & -27 \\
\hline & 7 & Tessar SOI & 148 & 100 & $9 \times 12$ & pg & 0 \\
\hline The New & 1 & Uran-9 & 100 & 250 & $30 \times 40$ & pv & +10 \\
\hline series. & 2 & Uran-9 & 100 & 250 & $30 \times 40$ & $\mathrm{pv}$ & -10 \\
\hline From & 3 & Triplet & 100 & 500 & $22 \times 15$ & pg & +30 \\
\hline 09.04 .1959 & 4 & Vierlinser & 160 & 720 & $13 \times 18$ & $\mathrm{pg}$ & +18 \\
\hline to & 5 & Vierlinser & 160 & 720 & $13 \times 18$ & pg & -18 \\
\hline \multirow[t]{2}{*}{08.06 .1966} & 6 & Industar 17 & 100 & 500 & $22 \times 15$ & $\mathrm{pg}$ & -33 \\
\hline & 7 & Uran-12 & 200 & 500 & $18 \times 24$ & $\mathrm{pg}, \mathrm{pv}$ & 0 \\
\hline The III & 1 & Uran-9 & 100 & 250 & $30 \times 40$ & pv & +13 \\
\hline series. & 2 & Uran-9 & 100 & 250 & $30 \times 40$ & pv & -13 \\
\hline From & 3 & UNAR & 120 & 600 & $16 \times 11$ & pg & +23 \\
\hline 09.06 .1966 & 4 & Vierlinser & 160 & 720 & $13 \times 18$ & pg & +08 \\
\hline until & 5 & Vierlinser & 160 & 720 & $13 \times 18$ & pg & -08 \\
\hline \multirow[t]{2}{*}{ now } & 6 & UNAR & 120 & 600 & $16 \times 11$ & $\mathrm{pg}$ & -23 \\
\hline & 7 & Uran-12 & 200 & 500 & $18 \times 24$ & $\mathrm{pv}$ & 0 \\
\hline
\end{tabular}


$\alpha$ And, $\delta$ And, $\beta$ And, $\gamma$ And, $\alpha$ Per, $\alpha$ Tau, $\alpha$ Aur, $\eta$ Gem, $i$ Cnc, $\gamma$ Leo, $\delta$ Leo, $\beta$ Leo, $\varepsilon$ Vir, $\alpha$ Boo, $\alpha \mathrm{CrB}, \zeta$ Her, $\delta$ Her, $\mu$ Her, $\gamma$ Oph, $\alpha$ Lyr, $\zeta$ $\mathrm{Aql}, \beta \mathrm{Cyg}, \zeta \mathrm{Cyg}, \beta \mathrm{Peg}$. In the New series the following stars were added: 41 Ari, $\zeta$ Per, $\zeta$ Gem, $\lambda$ Leo, $\beta$ Vir, 70 Vir, $\zeta$ Boo, $\gamma$ Her, $\gamma$ Lyr, $\gamma$ Cyg, $\epsilon$ Peg, but $\mu$ Her was discarded. These 34 stars have been used in the III series. The shifts of the plate centers (in degrees of declination) from the positions of guide stars are listed in Table 3. With exposure times of 30 minutes and covering a 2-hour right ascension zone at once photos can be taken of all the apparent celestial sphere each night by using guide stars located in declination between $+10^{\circ}$ to $+40^{\circ}$.

The material of the collections is used by professionals and amateurs to study properties and brightness variations of different celestial bodies. However, precise $\mathrm{BV}$-photometry is possible only with 7-camera astrograph material.

Table 4. Colour coefficient $c(b)$ and $c(v)$ of photometric systems of the 7-camera astrograph calculated by A.N.Rudenko in the form $m(i)=V+c(i) \cdot(B-V)$ and with a common error of determination $\mathrm{dm}$

\begin{tabular}{|c|c|c|c|c|c|c|c|}
\hline Cameras & 1 & 2 & 3 & 4 & 5 & 6 & 7 \\
\hline \multicolumn{8}{|c|}{ The Old series - JD $2436039-2436668$} \\
\hline c(b) & +0.06 & $-0.18-$ & -0.21 & \multicolumn{2}{|c|}{$-0.37-0.06$} & -0.12 & -0.23 \\
\hline $\mathrm{dm}$ & 0.10 & 0.13 & 0.12 & \multicolumn{2}{|c|}{$0.10 \quad 0.12$} & 0.11 & \multirow[t]{2}{*}{0.07} \\
\hline$c(v)$ & +0.19 & +0.25 & \multicolumn{3}{|c|}{ from JD 2436281} & & \\
\hline $\mathrm{dm}$ & 0.24 & 0.14 & \multicolumn{3}{|c|}{ from JD 2436281} & & \\
\hline \multicolumn{8}{|c|}{ The New series - JD $2436690-2439286$} \\
\hline$c(b)^{\prime}$ & \multirow{2}{*}{\multicolumn{2}{|c|}{$\begin{array}{l}\text { to JD } 2439038 \\
\text { to JD } 2439038\end{array}$}} & -0.27 & \multicolumn{2}{|c|}{$-0.33-0.33$} & -0.14 & -0.04 \\
\hline $\mathrm{dm}$ & & & \multirow{2}{*}{\multicolumn{2}{|c|}{$\begin{array}{lr}0.07 & 0.24\end{array}$}} & 0.15 & 0.12 & \multirow[t]{2}{*}{0.09} \\
\hline$c(v)^{\prime}$ & +0.23 & +0.18 to JD 2439038 & & & & & \\
\hline $\mathrm{dm}$ & 0.28 & \multicolumn{3}{|c|}{0.18 to JD 2439038} & & & \\
\hline$c(b) "$ & \multicolumn{3}{|c|}{ from JD $2439050-0.07$} & \multicolumn{2}{|c|}{$-0.26-0.31$} & -0.14 & \\
\hline $\mathrm{dm} "$ & from JD & 2439050 & 0.07 & 0.10 & 0.24 & 0.11 & \\
\hline $\mathrm{c}(\mathrm{v}) "$ & +0.20 & \multicolumn{5}{|c|}{+0.17 from JD 2439050 (1,2 cameras $)$} & \multirow{2}{*}{$\begin{array}{r}+0.22 \\
0.12\end{array}$} \\
\hline $\mathrm{dm} "$ & 0.13 & \multicolumn{3}{|c|}{0.20 from JD 2438930} & $(7 \mathrm{ca}$ & nera) & \\
\hline \multicolumn{8}{|c|}{ The III series - JD 2439291 - up till now } \\
\hline$a(b)^{\prime}$ & \multicolumn{2}{|c|}{ to JD 2441983} & \multicolumn{3}{|c|}{$-0.32-0.45-0.31$} & \multicolumn{2}{|l|}{-0.34} \\
\hline $\mathrm{dm}^{\prime}$ & \multicolumn{2}{|c|}{ to JD 2441983} & 0.15 & \multirow{2}{*}{\multicolumn{2}{|c|}{$\begin{array}{ll}0.12 & 0.12\end{array}$}} & 0.09 & \\
\hline $\mathrm{c}(\mathrm{v})^{\prime}$ & +0.23 & +0.27 & & o JD 2441274 & & & +0.14 \\
\hline dm & 0.16 & 0.17 & & o JD 2441274 & & & 0.11 \\
\hline$c(b) "$ & to JD 2 & $2444074-$ & -0.33 & $-0.03-$ & -0.06 & -0.07 & \\
\hline dm" & to JD 2 & 2444074 & 0.19 & 0.12 & 0.08 & 0.18 & \\
\hline$c(v) "$ & +0.34 & +0.34 & & up till now & & & +0.32 \\
\hline $\mathrm{dm} "$ & 0.15 & 0.12 & & up till now & & & 0.13 \\
\hline$c(b) "$ & from JD & 2444075 & -0.29 & $-0.26-$ & -0.02 & -0.07 & \\
\hline dm" & from JD & 2444075 & 0.16 & 0.09 & 0.10 & 0.17 & \\
\hline
\end{tabular}

